\title{
Proposta de Ações de Educação Ambiental em São Tomé e Príncipe
}

\author{
FURTADO, Osvaldo Vaz ${ }^{1}$ \\ KANIKADAN, Andrea Yumi Sugishita
}

\section{RESUMO}

Este estudo tem como objetivo analisar o processo de coleta, tratamento, destinação final dos resíduos sólidos e a partir disso propor ações de educação ambiental em Água Grande, distrito de São Tomé e Príncipe (STP). O intuito é descrever as principais características que retratam a situação local. O estudo traz um levantamento teórico sobre poluição ambiental, resíduos sólidos urbanos e educação ambiental. Foi conduzida uma pesquisa qualitativa, com técnicas de análise documental e bibliográfica. Pôde-se verificar que o distrito de Água Grande carece de boas práticas para a coleta, separação, tratamento e a sua destinação final, englobando todos os processos de gerenciamento dos Resíduos Sólidos Urbanos (RSU). Nessa perspectiva, o estudo apresenta sugestão relacionada à educação ambiental desde a infância, de modo que exista um envolvimento integrado da gestão pública, sociedade civil e indústrias privadas. Tudo isso levando-se em consideração a questão da saúde pública no país.

São Tomé e Príncipe. Educação ambiental. Gestão de resíduos sólidos.

\section{Proposition of actions related to environmental education in São Tomé and Príncipe}

\section{ABSTRACT}

This study aims to analyze the process of collection, treatment, final disposal of solid waste in order to propose policies in environmental education in Água Grande, district of São Tomé and Príncipe (STP). The aim is to describe the main characteristics that portray the local situation. The study provides a theoretical survey on environmental pollution, solid urban waste and environmental

\footnotetext{
${ }^{1}$ Mestrando em políticas públicas e desenvolvimento pela da Universidade Federal da Integração Latino-Americana (UNILA). E-mail: vazfurtado1993@gmail.com. Lattes: http://lattes.cnpq.br/2300105710619243. Orcid: https://orcid.org/0000-0002-9562-3600. 2 Doutora em Ciências, professora adjunta do curso de Administração Pública do Instituto de Ciências Sociais Aplicadas da Universidade da Integração Internacional da Lusofonia AfroBrasileira (ICSA/UNILAB). E-mail: akanikadan@unilab.edu.br. Lattes: http://lattes.cnpq.br/8061259946864185. Orcid: https://orcid.org/0000-0001-5057-4801.
}

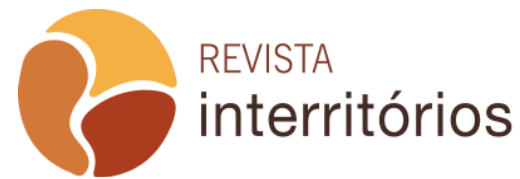


education. A qualitative research was conducted, using techniques of documentary and bibliographic analysis. It was possible to verify that the district of Água Grande lacks of good practices for the collection, separation, treatment and its final destination, encompassing all the processes of management of Urban Solid Waste (MSW). In this perspective, the study presents a suggestion related to environmental education since childhood, so that there is an integrated partnership of public management, civil society and private industries. All of this taking into account the issue of public health within the country.

São Tomé and Príncipe. Environmental education. Solid waste management.

\section{Propuesta de acciones de educación ambiental en Santo Tomé y Príncipe}

\section{RESUMEN}

Este estudio tiene como objetivo analizar el proceso de recolección, tratamiento, disposición final de residuos sólidos y proponer acciones de educación ambiental en Água Grande, distrito de Santo Tomé y Príncipe (STP). El objetivo es describir las principales características que retratan la situación local. El estudio proporciona un levantamiento teórico sobre contaminación ambiental, residuos sólidos urbanos y educación ambiental. Se realizó una investigación cualitativa, utilizando técnicas de análisis documental y bibliográfico. Se pudo constatar que el distrito de Água Grande carece de buenas prácticas para la recolección, separación, tratamiento y su destino final, abarcando todos los procesos de gestión de Residuos Sólidos Urbanos (RSU). En esta perspectiva, el estudio presenta una sugerencia relacionada con la educación ambiental desde la infancia, para que exista un involucramiento integrado de la gestión pública, la sociedad civil y las industrias privadas. Todo ello teniendo en cuenta el tema de la salud pública en el país.

Santo Tomé y Príncipe. Educación ambiental. Manejo de residuos sólidos.

\section{Proposta di azioni di educazione ambientale a São Tomé e Príncipe}

\section{SOMMARIO}

Questo studio si propone di analizzare il processo di raccolta, trattamento, smaltimento finale dei rifiuti solidi e proporre azioni di educazione ambientale ad Água Grande, distretto di São Tomé e Príncipe (STP). L'obiettivo è descrivere le principali caratteristiche che ritraggono la situazione locale. Lo studio fornisce un'indagine teorica su inquinamento ambientale, rifiuti solidi urbani e educazione

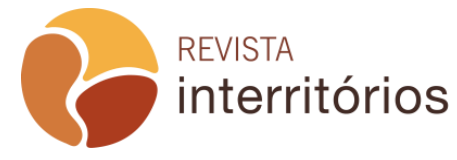

Interritórios | Revista de Educação Universidade Federal de Pernambuco, Caruaru, BRASIL | V.6 N.12 [2020] 
ambientale. È stata condotta una ricerca qualitativa, utilizzando tecniche di analisi documentaria e bibliografica. È stato riscontrato che il distretto di Água Grande manca di buone pratiche per la raccolta, la separazione, il trattamento e la sua destinazione finale, che comprende tutti i processi di gestione dei rifiuti solidi urbani (RSU). In questa prospettiva, lo studio presenta un suggerimento relativo all'educazione ambientale fin dall'infanzia, in modo che ci sia un coinvolgimento integrato della gestione pubblica, della società civile e delle industrie private. Tutto questo tenendo conto della questione della salute pubblica nel Paese.

Sao Tome e Principe. Educazione ambientale. Gestione dei rifiuti solidi.

\section{INTRODUÇÃO}

O conceito de resíduos sólidos está ligado ao processo civilizatório humano no qual se acredita que os primeiros acúmulos de materiais residuais foram originados a partir do momento em que este deixou-se fixar em determinados locais, passando a conviver com as sobras (SANTAELLA et al., 2014). Dentro desse pressuposto pode-se afirmar que o aumento do lixo nas últimas décadas em centros urbanos se dá por causa da concentração do ser humano em lugares específicos.

Com o processo acelerado de produção de bens de consumo do sistema capitalista, tem-se cada vez mais a introdução de matérias que o ambiente não consegue absorver, causando depredação da natureza e poluição. As pessoas acabam se habituando tanto com esta situação em seu cotidiano que nem percebem a poluição visual. $O$ comodismo e a busca pelo conforto têm levado os seres humanos à exploração de diferentes maneiras dos recursos naturais gerando produtos prejudiciais à saúde e ao próprio meio ambiente. No âmbito da industrialização, houve aumento da fabricação de produtos inorgânicos, tais como o vidro, plástico, metais, borracha gerando aumento na produção de resíduos e dificultando a decomposição, pois requerem um tempo muito grande para tal (ANDREOLI, 2014).

A má gestão dos resíduos sólidos pode gerar diversos problemas socioambientais, econômicos e de saúde pública. Diante deste cenário é imprescindível observar o papel dos poderes públicos, ou seja, Gonzalez (2009) define que a gestão de resíduos urbanos está diretamente relacionada com a tomada de decisão dos gestores municipais (prefeitos e gestores do sistema), levando em consideração que eles são os únicos responsáveis por decidir como 
e com quais recursos irão enfrentar os problemas. Eles têm uma grande responsabilidade na aplicação de políticas de gestão de resíduos sólidos, incluindo diversos tipos de políticas públicas. Essa atuação passa pela formulação e implementação de políticas para o tratamento dos resíduos sólidos e deve estar voltada para a melhoria e bem-estar da população. Neste sentido é necessário avultar a importância de gestão e de planejamento no monitoramento e avaliação dos impactos destas mesmas políticas. Nessa ótica o presente trabalho tem como objetivo analisar como se dá o processo de coleta, tratamento, destinação final dos resíduos sólidos e propor ações de educação ambiental na cidade de São Tomé, mais concretamente no distrito de ÁguaGrande em São Tomé e Príncipe (STP). Ainda buscou-se descrever as principais características e aspectos que retratam a situação local e também averiguar os principais problemas da gestão dos resíduos sólidos urbanos e os desafios enfrentados pelos órgãos responsáveis pela sua gestão no distrito.

Trata-se de estudo de natureza descritivo-exploratória, dentro de uma abordagem qualitativa. Utilizou-se a análise documental e bibliográfica (SILVA et al., 2009), levando em consideração os aspectos da gestão dos resíduos sólidos e o próprio conceito de educação ambiental. Os principais instrumentos analisados foram: o Plano Nacional de Gestão Integrada de Resíduos Sólidos Urbanos - São Tomé e Príncipe (PNGIRS) (TESE; ECOGESTUS, 2018) e o Recenseamento Geral da População e Habitação (INE, 2012). Ainda, para realização deste trabalho efetuou-se levantamento bibliográfico que de acordo com Gerhardt (2009) é feito a partir do levantamento de referências teóricas já analisadas e publicadas por meios escritos e eletrônicos como livros, artigos científicos, web sites, tais como Jornal Téla Nón, Instituto Nacional de Estatísticas (INE), EcoGestus, GIRSU e o Web Site do Ministério de MeioAmbiente em São Tomé e Príncipe (STP).

O estudo justifica-se pelo fato de não ter sido colocada como prioridade nas pautas da liderança, que, segundo VEIGA (2012), Água Grande é o local onde se produz a maior quantidade de resíduos sólidos do país. Outra razão é a importância da implementação de educação ambiental na gestão dos resíduos sólidos urbanos para melhoria da situação atual quanto aos problemas que se encontram no distrito, contando com a sua relevância no bem-estar de todos os distritos e da população são-tomeense, para que possam ter uma vida saudável longe das doenças provenientes dos resíduos sólidos. Além disso, é o menor distrito do país, ao mesmo tempo, concentra a maior parte da população, e é onde um dos autores residiu e conviveu por muitos anos com a questão dos resíduos sólidos.

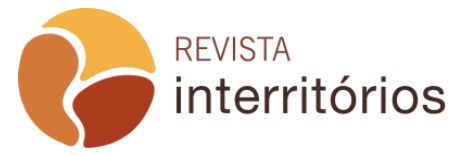




\title{
Referencial teórico
}

\author{
Poluição ambiental
}

À medida que a população aumenta, convenciona-se haver grande acréscimo em termos de produção e consumo dos itens industrializados, o que resulta em enormes problemas para o meio ambiente. Dentre diversos problemas ambientais, há aqueles que surgem por meio das catástrofes naturais como: vendavais, terremotos e inundações. Porém, pode-se afirmar que há problemas que são causados pelas intervenções humanas, contribuem em grande escala no abarco da poluição ambiental de diversas maneiras, com a inserção de resíduos sólidos, indústrias de irrigação, acidentes no transporte de cargas, dentre muitas outras (BRILHANTE, 1999). Os problemas causados recaem muitas vezes nas características das propriedades físicas, químicas e biológicas utilizadas, que quando descartadas no ambiente, tornam-se impróprias, não somente para os seres humanos, mas, também para outras espécies. A exploração por parte da humanidade, de forma inadequada dos recursos naturais, acaba por gerar grandes impactos ao meio ambiente, principalmente quando não se recicla, resultando em poluição.

A poluição ambiental se dá por diversos tipos, a saber: poluição biológica das águas; poluição do ar que se constitui de uma mistura perigosa de gases residuais; poeiras e poluição do solo e do subsolo que consiste na deposição, disposição, descarga, infiltração, acumulação, injeção ou aterramento no solo. Do ponto de vista ecológico, segundo Brilhante (1999), poluição é definida como qualquer alteração da composição e das características do meio que cause perturbações nos ecossistemas, ou seja, são transformações que causam desequilíbrio ao meio ambiente.

Resíduos sólidos urbanos e seu gerenciamento

O termo "Resíduos Sólidos Urbanos (RSU)" associa-se a todos os resíduos domésticos ou provenientes de centros urbanos com características semelhantes produzidos pelos cidadãos nos respectivos domicílios (ECOGESTUS, 2016). 
O crescimento desordenado da população e o aparecimento de grandes indústrias fez com que aumentasse o consumo, e com isso gerou-se maior quantidade de resíduos que, de modo geral, possui manejo e destinação impróprios, causando efeitos negativos ao meio ambiente. De acordo com as pesquisas feitas por especialistas, observou-se que, a concentração de grande número de pessoas em determinada localidade, tendencialmente, resulta em grande produção de resíduos sólidos. A concentração populacional e a existência de indústrias tornaram uma das grandes causas para o aumento, tanto da poluição como também dos resíduos sólidos.

Resíduos sólidos do ponto de vista de Silva (2015), podem ser considerados como qualquer material que seu proprietário ou produtor não considera mais com valor suficiente para conservá-lo. Os "resíduos sólidos resultam da atividade do ser humano, sendo, por isso, considerado inesgotável, além de diretamente proporcional à intensidade industrial e ao aumento populacional" (SOARES; SALGUEIRO; GAZINEU, 2007, p.01). Segundo a norma brasileira NBR 10.004 de $1987^{3}$ resíduos sólidos são aqueles resíduos nos estados sólido e semissólido, que resultam de atividades da comunidade de origem industrial, doméstica, hospitalar, comercial, agrícola, de serviços e de varrição. Ainda, de acordo com Almeida (2009), pode-se incluir nesse conceito os lodos provenientes de sistemas de tratamento de água, aqueles gerados em equipamentos e instalações de controle de poluição, bem como determinados líquidos cujas particularidades tornam inviável o seu lançamento na rede pública de esgotos ou corpos de água. Logo, os resíduos sólidos compreendem todos os restos domésticos e resíduos não perigosos, tais como os resíduos comerciais e institucionais, os lixos da rua e os entulhos de construção (UNCED, 1992 apud POLZIN, 2004, p.280).

Os resíduos sólidos podem ser classificados quanto à sua natureza física, composição química e sua origem (OLIVEIRA, 2012).

\section{Quadro 1 - As características de resíduos sólidos}

\begin{tabular}{|l|l|l|}
\hline $\begin{array}{c}\text { Resíduos } \\
\text { sólidos }\end{array}$ & \multicolumn{1}{|c|}{ Natureza/Fontes Geradoras } & \multicolumn{1}{c|}{$\begin{array}{c}\text { Características dos Resíduos } \\
\text { produzidos }\end{array}$} \\
\hline Domiciliares & $\begin{array}{l}\text { Todos os resíduos originários de } \\
\text { atividades domésticas em } \\
\text { residências urbanas, edifícios, } \\
\text { empresas e escolas. }\end{array}$ & $\begin{array}{l}\text { Sobras de alimentos, produtos } \\
\text { deteriorados, lixo de banheiro, } \\
\text { embalagens de papel, vidro, metal, }\end{array}$ \\
\hline
\end{tabular}

${ }^{3} \square$ http://www.suape.pe.gov.br/images/publicacoes/normas/ABNT_NBR_n_10004_2004.pdf 
Proposta de ações de educação ambiental em São Tomé e Príncipe

\begin{tabular}{|l|l|l|}
\hline & & $\begin{array}{l}\text { plástico, isopor, longa vida, pilhas, } \\
\text { eletrônicos, baterias, fraldas e outros. }\end{array}$ \\
\hline Comerciais & $\begin{array}{l}\text { Aqueles produzidos pelos centros } \\
\text { comerciais, bares e restaurantes. }\end{array}$ & $\begin{array}{l}\text { Embalagens de papel e plástico, sobras de } \\
\text { alimentos e muitos outros. }\end{array}$ \\
\hline $\begin{array}{l}\text { Públicos ou de } \\
\text { limpeza urbana }\end{array}$ & $\begin{array}{l}\text { Conjunto de todos os tipos de } \\
\text { resíduos gerados nas cidades e } \\
\text { coletados pelo serviço local } \\
\text { originários da varrição, limpeza de } \\
\text { logradouros, poda e vias públicas } \\
\text { e outros serviços de limpeza } \\
\text { urbana. }\end{array}$ & Poeira, folhas, papéis e outros. \\
\hline Industrial & $\begin{array}{l}\text { Todos provenientes de serviços } \\
\text { industriais. }\end{array}$ & $\begin{array}{l}\text { Cinzas, lodos, óleos, resíduos alcalinos ou } \\
\text { ácidos, plásticos, papel, madeira, fibras, } \\
\text { escórias } \\
\text { e outros. }\end{array}$ \\
\hline $\begin{array}{l}\text { Portos, } \\
\text { aeroportos, } \\
\text { terminais }\end{array}$ & $\begin{array}{l}\text { Resíduos coletados nesses locais } \\
\text { que podem transportar doenças } \\
\text { vindo de outros locais do mundo. }\end{array}$ & $\begin{array}{l}\text { Resíduos sépticos, sobras de alimentos, } \\
\text { material de higiene e asseio pessoal e } \\
\text { outros. }\end{array}$ \\
\hline Agrícola & $\begin{array}{l}\text { Gerados pelas atividades } \\
\text { agrícolas que parte dos produtos } \\
\text { agropecuários. }\end{array}$ & $\begin{array}{l}\text { Embalagens de agrotóxicos, pneus e óleos } \\
\text { usados, embalagens de medicamentos } \\
\text { veterinários, plásticos e outros. }\end{array}$ \\
\hline $\begin{array}{l}\text { Construção } \\
\text { civil }\end{array}$ & $\begin{array}{l}\text { Obras e reformas residenciais e } \\
\text { comerciais. }\end{array}$ & $\begin{array}{l}\text { Madeira, cimento, blocos, pregos, gesso, } \\
\text { tinta, latas, cerâmicas, pedra, areia e } \\
\text { outros. }\end{array}$ \\
\hline Hospitalares & $\begin{array}{l}\text { Aqueles que sobram das } \\
\text { atividades hospitalares e centros } \\
\text { de saúde. }\end{array}$ & $\begin{array}{l}\text { Objetos perfurocortantes, peças } \\
\text { anatômicas, utensílios de vidro, recipientes } \\
\text { rígidos entre outros. }\end{array}$ \\
\hline $\begin{array}{l}\text { Aqueles provenientes de processo } \\
\text { de mineração, solo removido. }\end{array}$ & $\begin{array}{l}\text { Estéreis (materiais escavados) e rejeitos } \\
\text { (resultantes do processo de } \\
\text { beneficiamento) (SILVA et al., 2012). }\end{array}$ \\
\hline
\end{tabular}

Fonte: Adaptado de Jacobi e Besen (2011).

A gestão local desempenha um papel decisivo para a gestão de resíduos sólidos urbanos pois é neste espaço onde ocorrem as tomadas de decisão e onde se encontram as pessoas que mais conhecem a realidade local. Leme (2010) atenta que pode haver diversidade de realidades de um local para outro, tais como: tamanho do local, renda per capita da população, o grau de mobilização social, a diversidade populacional (comunidades tradicionais, industriais, população rural ou urbana), capacidade técnica e escolaridade para lidar com questões ambientais, grau de captura do poder local. Ademais, há o desafio para se estabelecer políticas públicas que devem envolver a sociedade (LEME, 2010). É preciso compreender que as políticas ambientais são complexas: necessidade de dialogar, de forma horizontal, com as políticas 
setoriais a fim de incorporar critérios ambientais na concepção de todas as políticas públicas, especialmente as de desenvolvimento (ARRETCHE, 2006).

Educação ambiental

As práticas de educação ambiental devem servir para mudanças de atitudes, comportamentos e mudança de uma certa realidade que acaba afetando o meio ambiente (SANTOS, 2017). Para que essas mudanças aconteçam, é necessário uma certa atenção no que tange a mentalidade das pessoas, ou seja, a conscientização da população quanto à sua responsabilidade no que concerne o meio ambiente. Santos (2017) salienta ainda que, as mudanças não devem se limitar a aspectos comportamentais, do indivíduo, mas sim em sua inserção na sociedade, de modo mais amplo, político, crítico, social. Nessa perspectiva, a educação ambiental tem como função promover aquisição dos conhecimentos, dos valores, dos comportamentos e das competências necessárias para que os cidadãos possam participar de forma responsável na prevenção dos problemas ambientais e sociais (CRUZ; FERNANDES; MARTINS, 2017).

Na visão de Silva et al. (2012), as ações da educação ambiental, por constituir um processo de gerenciamento informativo e formativo dos indivíduos, acabam por desenvolver habilidades e modificam atitudes em relação ao meio, tornando a comunidade consciente de sua realidade.

Partindo desse conceito, Jacobi (2011) afirma que o uso da Educação Ambiental na gestão de resíduos sólidos é de extrema importância para o seu adequado gerenciamento, pois, a partir dela se inicia o processo de mudança de hábitos dos indivíduos para uma destinação adequada dos resíduos.

Esse conhecimento pode ser facilitador para os líderes na criação de políticas voltadas ao meio ambiente, especialmente na gestão dos resíduos sólidos.

\section{O caso de São Tomé e Príncipe}

Gestão de resíduos sólidos urbanos em São Tomé

Importa contextualizar historicamente as duas ilhas, para melhor conhecer o lócus de estudo. As ilhas de São Tomé e Príncipe (STP) tiveram sua

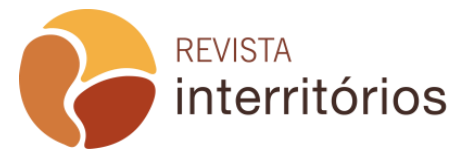


colonização entre 1470-1471, pelos navegadores portugueses, João de Santarém e Pêro Escobar. A partir disso, o país ficou sob a tutela portuguesa até 12 de julho de 1975, data em que foi proclamada a sua independência. São Tomé e Príncipe localizam-se no Golfo da Guiné, separado pelo Oceano Atlântico a $250 \mathrm{~km}$ da costa ocidental africana. Sua superfície total é de 1001 $\mathrm{km}^{2}$ de área, e está distribuída da seguinte forma: ilha de São Tomé, $859 \mathrm{~km}^{2} \mathrm{e}$ ilha de Príncipe, $142 \mathrm{~km}^{2}$ (CASTAÑO, 2012). A distância que as separa é de 145 $\mathrm{km}$, tendo aproximadamente 200 mil habitantes em todo território nacional. De acordo com Castaño (2012), o país possui população predominantemente jovem, com economia marcada por forte dependência do exterior e do cultivo de alguns produtos para exportação como o cacau que conta com maior destaque internacional, além do café, baunilha e coco.

As duas ilhas, por terem sido colonizadas pelos portugueses, têm como idioma falado pela maioria da população, o português, fazendo parte tanto da comunidade dos Países Africanos de Língua Oficial Portuguesa - PALOP como da Comunidade dos Países de Língua Portuguesa - CPLP. Para além do português ainda conta com alguns crioulos, como: forro e angolar, em São Tomé; e os minu ié, na llha Príncipe, dentre outras oriundas de outros países africanos (CASTAÑO, 2012).

A república democrática de STP está constituída por sete distritos, nomeadamente: Água Grande, Cantagalo, Caué, Lembá, Lobata, Mé-Zochi e Pagué. Levando em consideração os dados de Instituto Nacional de Estatística (INE, 2012), Água Grande é a capital do país, e cobre 17 quilômetros quadrados, sendo o menor dos 7 distritos em termos de área, mas é o maior quanto ao número de habitantes, com aproximadamente 54.300 residentes; ou seja, onde se concentra a maior parte da população. Diariamente a cidade de São Tomé produz 50 toneladas de lixo ${ }^{4}$ (VEIGA, 2012). Diante dos grandes produtores de resíduos sólidos, torna uma representação quase insignificante, mas dada a dimensão do país e sua estrutura, a quantidade de lixo gerada acaba se tornando muito preocupante. A coleta e tratamento de lixos são de inteira responsabilidade das câmaras distritais. Com base no estudo efetuado (ECOGESTUS, 2016), verificou-se que o problema central na Gestão de RSU em São Tomé e Príncipe

\footnotetext{
${ }^{4}$ As médias per capta diária dos grandes produtores mundial de resíduos sólidos segundo Galeffi, (2013): Estados Unidos de América (EUA) 2,5 kg de resíduos produzidos diariamente por cada habitante, em média, por cada cidadão em um único dia, de modo geral com o total de 624 mil toneladas por dia; Brasil a geração per capita de resíduos sólidos passa de 1,06 quilo $(\mathrm{kg})$ ao dia em 2014, para $1,07 \mathrm{~kg}$ ao dia em 2105.
} 
reside na gestão inadequada de RSU da qual resultam fortes impactos a nível ambiental, social e econômico que minam as potencialidades de desenvolvimento da República Democrática de São Tomé e Príncipe (RDSTP).

O consumo da população tem causado grandes impactos ao meio ambiente sobretudo na poluição do solo, visual e sonora. A cidade de São Tomé já foi considerada a cidade mais bonita e mais limpa da África (LISBOA, 2017). Hoje, com acúmulo de pessoas em lugares específicos que são os centros urbanos, acaba por gerar lixos de forma exorbitante. Com esse aumento, o lixo passou a tomar conta das ruas e becos do país, causando diversos tipos de poluição dentre eles do ar, visual e do solo.

Em STP nas últimas décadas, assinala Carvalho (2009), percebe-se diversos fenômenos graves na degradação em diferentes ecossistemas tanto terrestres como aquáticos que advém de inúmeros razões como: desmatamento para o cultivo da terra; abate descontrolado de árvores; extração abusiva e descontrolada da areia; poluição dos solos e sistemas aquáticos gerados por vários resíduos, dentre as demais. Essas razões são agravadas por indivíduos que não são conscientizados com o processo de educação ambiental, por essa razão não hesitam em largar seus desperdícios como garrafas vazias, sacos de plástico e outros materiais não orgânicos no solo, nas praias, no mar, nos rios, nas ruas e nos cantos dos seus quintais. Daí entra a grande importância do conceito da educação ambiental, partindo do princípio lógico da sua eficiência na questão de gestão de resíduos sólidos.

A má gestão de resíduos sólidos é problema bem comum em todos os distritos de STP, e tem trazido inúmeros problemas. Poderá ainda acarretar em outros futuramente, se, o problema de destinação, reutilização e hábitos não forem repensados. Um dos prejuízos que se pode citar é o descarte inadequado em terreno aberto, sem os devidos cuidados, causando contaminação do solo, lençóis freáticos e possível prejuízo à saúde da população local. Portanto, é necessário desenvolver certas políticas que possam melhorar a maneira como 0 distrito de Água Grande (capital de São Tomé) lida com a questão do lixo, como, por exemplo, a criação do aterro sanitário em parceria com outros distritos, ao invés de apenas despejo no lixão de "Penha" (forma como é conhecido na localidade) combatendo os problemas supracitados.

Coleta e tratamento de resíduos em São Tomé

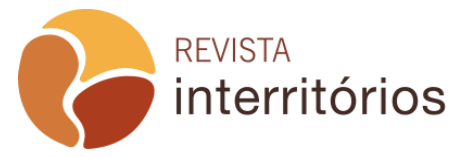


A coleta dos resíduos sólidos é a parte mais visível para a população, portanto, a mais passível de crítica e também participação, por isso é necessário um adequado planejamento dos serviços de coleta, pois eles representam cerca de 50 a 80\% do custo de operação de limpeza pública (SOARES; SALGUEIRO; GAZINEU, 2007). O processo de coleta dos lixos na cidade de São Tomé e arredores conta primeiramente com a instalação dos contentores em diversos pontos da capital, esses que não contam com separação seletiva dos resíduos sólidos, são denominados de Jójó.

Em segundo lugar, cabe aos coletores dos caminhões da câmara distrital acompanhados dos presidiários que, para cumprimento de suas penas, trabalham juntamente no processo de limpeza das ruas. Para que isso aconteça da melhor forma, a população produtora do lixo deveria depositar corretamente nos locais adequados, mas isso não consta na realidade em São Tomé. Uma das razões é que nem todos os moradores têm acesso aos contentores, utilizamse do quintal como seu próprio lixão fazendo queimada e enterro dos resíduos que muitas vezes acabam por trazer consequências negativas para a saúde. Outra razão é a falta de informação relacionado a questão em causa.

A má gestão na coleta dos resíduos envolvendo a separação de lixos de forma inadequada, pode ser comprovada com os relatos comuns de se ouvir, quando a população diz que "o jójó" enche e a Câmara não passa para recolher. Os próprios responsáveis autárquicos acabam por argumentar que há necessidade de mais e maiores contentores. Se os contentores não são suficientes por si só, a demora na coleta acaba por facilitar o aumento dos lixos nas cidades e ruas e desta feita acabam por não ter capacidade para assegurar a produção de vários dias, isto por causa da falta de meios em que se encontra a câmara distrital.

A falta de organização na gestão dos resíduos sólidos na cidade, justificada pela falta de condições e de materiais acaba por resultar em acúmulos de lixo pela capital e arredor, o que intensifica o que Leme (2010) salienta sobre a necessidade de haver uma capacitação para lidar com questões ambientais.

Embora exista o Plano Nacional de Gestão Integrada de Resíduos Sólidos Urbanos (PNGIRSU) de São Tomé e Príncipe, promovido pela Direção Geral do Ambiente (TESE; ECOGESTUS, 2018), há certa dificuldade em operacionalizar o plano. Afirma Veiga (2012) que cada câmara distrital trabalha de forma isolada quase sem ideia do que se passa no território vizinho, o que num cenário de poucos recursos e com meios escassos para consegui-los, dificulta o 
compromisso assumido por decreto, isto é, o da gestão de resíduos sólidos urbanos por parte das Câmaras Distritais.

O distrito de Água Grande está na pior situação nos últimos anos em matéria de gestão de resíduos, montes de lixo campeiam pela cidade de São Tomé e nos arredores a situação chega a um nível ainda pior, colocando em perigo a saúde humana (VEIGA, 2016). Os resíduos são divididos logo depois de serem depositados na lixeira, não existe tratamento final de resíduos sólidos urbanos de forma sustentável em São Tomé e Príncipe, apenas a reutilização das garrafas de vidro (ECOGESTUS, 2016). Estas, são realizadas pela Santa Casa da Misericórdia, com transformação na embalagem recolhida em pó e posterior utilização na construção civil. Todo esse quadro reforça a importância de uma gestão local que consiga dialogar com outros setores da sociedade numa perspectiva que leve a criação de políticas intersetoriais envolvendo a sociedade e seu ambiente (ARRECHTE, 2006; LEME, 2010).

Disposição final dos resíduos

O distrito de Água Grande possui apenas um lixão denominado de "lixeira de Penha", onde são depositados todos os tipos de lixos do distrito e também do distrito vizinho denominado Mé-Zochi. O lixão recebe todos os tipos de resíduos possíveis como animais mortos, produtos recicláveis e não recicláveis, ferros, pedra, tronco de árvores, garrafa dentre muitas outras espécies. A atual lixeira e vazadouro (Penha) não são controlados nem estão delimitados devidamente, ocorrendo o descarte em locais impróprios com potencial elevado de contaminação. A lixeira, de acordo com a sua estrutura e a sua prática de tratamento dos resíduos sólidos acaba ocasionando outros tipos de problemas, sobretudo os de saúde pública. Nesta mesma lixeira, também são depositados os resíduos provenientes do hospital central e dos postos de saúde. Os resíduos hospitalares segundo Téla Nón (2010) antes de serem levados no caminhão, são depositados numa enceradora local, para, em seguida, serem queimados a céu aberto, sem nenhum tipo de procedimento e controle; outros são enterrados, usando práticas não convenientes para o ambiente. Dessa maneira, pode-se observar o quão perigoso se torna à saúde das pessoas que residem nas localidades próximas e aos catadores que atuam nesse lixão, tornando ainda mais prejudicial ao meio ambiente. 
Os desafios da gestão e a educação ambiental

São Tomé e Príncipe é um país que viveu por muitos anos em constante instabilidade política; após a independência já foram trocados vários governos. Entretanto, isso afeta até hoje o país no que se remete a prática de boa gestão. Não poderia ser diferente os desafios enfrentados pelo atual gestor da câmara distrital de Água Grande na gestão dos resíduos sólidos urbanos, acumulando problemas de mandatos anteriores.

O maior desafio para o responsável municipal, em todo o processo, desde a coleta até o descarte final dos resíduos se dá na criação de um aterro sanitário, isto porque é extremamente complexo realizar todo o processo de tratamento dos resíduos, seguindo as políticas ambientais mais adequadas, para no final, o lixo acabar em um depósito irregular, que potencializa a contaminação do lençol freático, do ar e contribui para a proliferação de doenças. Com a criação do aterro sanitário para a região, é certo que aumentará a articulação interdistrital, sobretudo pela urgência em solucionar questão dos depósitos de lixo a céu aberto.

Pode-se afirmar que, o distrito de Água Grande é onde se produz maior quantidade de resíduos sólidos do país, isto de acordo com os dados do quarto recenseamento geral da população e habitação realizado no país (INE, 2012). É possível observar diversos problemas que afetam o processo de coleta e de tratamentos dos resíduos sólidos no distrito, levando em consideração as condições financeiras que o país apresenta. Cabe ressaltar que há diversos outros problemas no país, o que acaba por impactar na gestão dos distritos. Uma questão importante que não pode ser desconsiderada é a baixa escolaridade da população, ou seja, ainda em São Tomé e Príncipe há uma alta taxa de analfabetos, oriundos de zonas rurais e que ao descartarem o lixo gerado a partir do consumo de produtos industrializados ou mesmo lixo orgânico, o fazem sem que haja uma conscientização ambiental voltada para o descarte em meio urbano.

A partir das questões expostas, considerando-se os conceitos da educação ambiental, São Tomé e Príncipe, por viver ainda uma situação desconfortável em relação a gestão dos resíduos sólidos, poderá trabalhar na conscientização da população por meio da formação dos indivíduos mudando as atitudes e desenvolvendo valores em relação ao meio ambiente. Para que essa conscientização dos indivíduos ocorra, será necessário desenvolver práticas voltadas à educação de forma a tornar os 
indivíduos aptos a lidar com o problema desde sua infância. Um entendimento inicial dos diferentes tipos de resíduos sólidos (vide quadro 1) e suas formas de descarte pode ser um primeiro passo para que outras ações sejam delineadas, dado que essa ação de educação ambiental deve envolver não só a sociedade civil mas igualmente o setor industrial.

O país vem recebendo apoios internacionais com propostas para preservação do meio ambiente principalmente na limpeza, coleta, tratamento e disposição de resíduos sólidos, porém, ainda insuficientes para amenizar o problema em causa (TESE; ECOGESTUS, 2018). Um dos maiores motivos reside nessa falta de conscientização da população em lidar com a situação sobretudo na conservação dos resíduos nos lugares apropriados para que os agentes da coleta possam executar suas tarefas.

Para que a educação ambiental se torne um processo de mudança dos hábitos dos indivíduos em STP, sugere-se a inserção do tema em disciplinas que fazem parte da grade curricular nas escolas desde o ensino básico, ou seja, inserção de temáticas em escolas públicas de disciplinas que retratem a questão de preservação e conservação do meio ambiente. Para o ensino superior, estas disciplinas também são necessárias, pois é onde serão formados os quadros técnicos para atuar nas atividades comerciais e industriais do país. Ademais, seria recomendável também a criação de campanhas de sensibilização e motivação que tratassem dos processos de coleta, tratamento, conservação e a deposição final dos resíduos. As campanhas de sensibilização acabariam por influenciar todos os indivíduos, mesmo aqueles que possuem um nível de escolaridade mais baixo.

Quanto à motivação, recairia na coleta e no tratamento, com a criação de políticas de coleta solidária onde os indivíduos menos desfavorecidos seriam beneficiados com ajudas financeiras ou mesmo com produtos de necessidades básicas. $O$ projeto poderá contar com a ajuda da população, com ações voltadas para os catadores de materiais recicláveis, como parte do eixo de inclusão produtiva das pessoas em situação de extrema pobreza no distrito. Também seria muito útil uma criação de política pública voltada para a educação ambiental, um investimento que contará com mudança ao longo prazo com conscientização populacional sobre tratamento e conservação dos lixos. Para que haja coleta seletiva solidária em STP, espera-se primeiramente que busque identificar as principais demandas estabelecendo parcerias distritais para garantir capacitação, assistência e apoio técnico ao trabalho

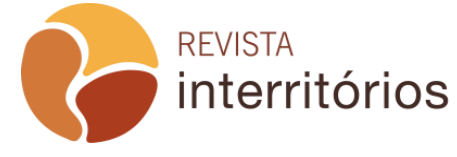


desenvolvido pelos catadores. Outro ponto que contribuirá muito para o distrito são campanhas de conscientização na utilização correta dos recipientes colocados nas ruas.

Nessa perspectiva, Marega (2011) defende que a coleta seletiva de lixo urbano poderia ser uma alternativa para a solução dos problemas socioambientais locais, reduzindo o volume de resíduos sólidos depositados nos aterros sanitários ou em lixões a céu aberto e, consequentemente, no meio ambiente, minimizando a extração de recursos naturais para fabricação de produtos diversos, além de atribuir maior tempo de vida útil aos aterros.

O país tem criado juntamente com as parcerias dos países estrangeiros projetos e programas para a preservação e melhoria do meio ambiente, principalmente no que tange a questão da coleta e tratamento dos resíduos sólidos em São Tomé e Príncipe (CRUZ; FERNANDES; MARTINS, 2017).

A organização do sistema de gestão de resíduos sólidos em São Tomé e Príncipe deverá assentar no conceito de responsabilidade partilhada, na qual todos os intervenientes sociais, que fazem parte do problema e da sua solução, devem participar ativamente em todo o processo (ECOGESTUS, 2016).

\section{CONSIDERAÇÕES FINAIS}

Cabe aqui destacar algumas dificuldades encontradas na realização deste estudo. Há falta de condições, meios e materiais, como monografias e artigos científicos, que retratem a realidade estudada no tocante à gestão de resíduos sólidos em São Tomé e Príncipe, por isso, não foi possível tornar a pesquisa mais enriquecedora. Isso mostra o tema pouco estudado no país e reforça a relevância deste estudo, ainda que com limitações.

O trabalho contou com a coleta de informações que se remeteram ao tratamento dos resíduos sólidos na cidade de São Tomé. As informações obtidas mostram, sintomaticamente, que a cidade carece de boas práticas para 0 tratamento, coleta, separação e sua destinação final, englobando assim todos os processos de gerenciamento de Resíduos Sólidos Urbanos (RSU). A câmara distrital exerce sua função em condições desfavorecidas, por esta razão, precisa criar planos para o melhoramento de seus serviços para lidar com falta de condições financeiras. 
A maior causa de acúmulos dos lixos na cidade de São Tomé advém de fatores tais como: a falta de assiduidade na retirada constante dos resíduos, causados por limitações financeiras e carência de materiais adequados para suprir as demandas. Levando em consideração que, o distrito de Água-Grande é a capital, portanto, localidade na qual se concentra a maioria da população e os maiores centros comerciais do país, logo, tendencialmente, é a região que produz grande parte do lixo de todo o território. Nesse caso, deveria ser o local a conter a maior quantidade de recursos no tocante à gestão da coleta $\mathrm{e}$ tratamento dos resíduos. A grande concentração dos resíduos sólidos em São Tomé não se limita apenas ao centro da cidade; a ausência de coleta frequente também tem sido um dos problemas nos bairros e zonas do distrito, onde os lixos são espalhados nas estradas por cães e as próprias pessoas, acabando por causar outros problemas para o próprio município.

A partir destas reflexões, pôde-se identificar os principais problemas que a Câmara Distrital de Água Grande enfrenta no processo de gestão de resíduos urbanos na cidade de São Tomé: falta de materiais para coleta de lixos, falta de aterro sanitário adequado, escassez de caminhões de coleta, falta de pessoas qualificadas na coleta de resíduos, ausência de política de tratamento, coleta seletiva e educação para população local.

Os resultados obtidos mostram que deve haver gestão integrada de resíduos sólidos no distrito, propondo desde coleta normal e seletiva, tratamento, reciclagem, até a destinação final nos aterros. Para realização dessas propostas com situação financeira crítica e falta de materiais que câmara enfrenta propôsse no contexto local do distrito Água Grande- São Tomé a implementação do Projeto Coleta Seletiva Solidária.

Com isso, acredita-se que poderia se amenizar a questão dos resíduos não apenas no distrito de Água-Grande, mas também em outras localidades do país, levando em consideração a dimensão do país e as condições financeiras e políticas que atualmente se encontra. Tudo isso, reforça o que Silva (2006) discorre sobre a necessidade de a educação ambiental ser questionadora e contribuir para uma intensa sensibilização, a partir de críticas e comportamentos estabelecidos que possibilita a atuação da sociedade.

\section{REFERÊNCIAS}


ALMEIDA, Paulo Santos de. Resíduos sólidos urbanos: Aterro Sustentável para Municípios de Pequeno Porte. Each, Florianópolis, v. 1, n. 26, p.1-26, 2009.

ANDREOLI, Cleverson V. et al. Resíduos sólidos: origem, classificação e soluções para destinação final adequada. Curitiba: FAEP, [2014]. p. 531-552. (Coleção Agrinho).

ARRETCHE, M. Federalismo e políticas sociais no Brasil: problemas de coordenação e autonomia. In: SARAVIA, E.; FERRAREZI, E. (Orgs.). Políticas públicas. Brasília: ENAP, v. 2, p. 91-110, 2006.

BARROS FILHO, Francisco de; GERALDO, Barão. Pesquisa quantitativa e pesquisa Qualitativa: Entenda a diferença [atualizado]. 2015. Disponível em: https://goo.gl/S5Jxef. Acesso em: 20 jan. 2018.

BRASIL. Constituição (2004). Norma Brasileira no 10004, de 30 de novembro de 2004. ABNT NBR. Norma Brasileira: ABNT NBR 10004. Segunda edição. ed. Rio de Janeiro, RJ: Abnt Nbr, 31 maio 2004. v. 1, n. 2, Seção 2, p. 02-71.

BRILHANTE, Ogenis Magno. Gestão e avaliação da poluição, impactos e risco na saúde ambiental. In: BRILHANTE, O.M.; CALDAS, L.Q.A (Coord.). Gestão e avaliação de risco em saúde ambiental [online]. Rio de Janeiro: FIOCRUZ, 1999. p. 19-74.

CARVALHO, Mariana. Ecologia, ambiente e educação ambiental em São Tomé e Príncipe. São Tomé: Cta, 2009. 71 p. 2.

CASTAÑO, Inês Filipa Abreu. São Tomé e Príncipe: Cultura (s)/Património(s)/Museu(s). 2012. 129 f. Dissertação (Mestrado) - Curso de Museologia, Ciências Sociais, Faculdade de Ciências Sociais e Humanas, São Tomé, 2012.

CRUZ, Gelsa Vera; FERNANDES, Luís Filipe; MARTINS, Maria da Conceição. Gestão sustentável dos resíduos sólidos urbanos em São Tomé e Príncipe: contributos da Educação Ambiental. Ambientalmente Sustentable, Portugal, v. 16, n.62, p.48-62, dez. 2017.

\section{ECOGESTUS. Plano de Ação para a Gestão Integrada de Resíduos Sólidos} Urbanos: São Tomé e Príncipe. 2. ed. São Tomé: Tese, 2011-2016. 94 p. 2.

GALEFFI, Carlo. Quem produz mais lixo no mundo. 2013. PRS. Disponível em: https://portalresiduossolidos.com/quem-produz-mais-lixo-no-mundo/. Acesso em: 23 mar. 2018.

GERHARDT, Tatiana Engel; SILVEIRA, Denise Tolfo (Org.). Métodos de pesquisa. Rio Grande de Sul: UFRGS, 2009. 120 p. (Série educação à distância). FNDE. 
INE. RECENSEAMENTO GERAL DA POPULAÇÃO E HABITAÇÃO - 2012. 5. ed. São Tomé: Instituto Nacional de Estatística, 2012. 163 p.

JACOBI, Pedro Roberto; BESEN, Gina Rizpah. Gestão de Resíduos Sólidos em São Paulo: desafios da sustentabilidade. Estud. av. [online]. 2011, v.25, n.71, p.135-158. Disponível em: http://dx.doi.org/10.1590/S0103-40142011000100010. Acesso em: 10 fev. 2018.

LEME, Taciana Neto. Os municípios e a política nacional do meio ambiente.

Planejamento e políticas públicas, ppp, n. 35, jul./dez. 2010.

LISBOA, Brany Cunha. São Tomé e Príncipe na categoria de lixo. 2017. Disponível em: https://www.telanon.info/suplemento/opiniao/2017/08/28/25152/sao-tome-eprincipe-na-categoria-de-lixo/. Acesso em: 28 mar. 2018.

MAREGA, A.C.P. Lixo urbano, um problema social e responsabilidade de todos. Cened, v. 1, n. 9, 08 abr. 2011.

OLIVEIRA, R. M. M. Gestão e gerenciamento de resíduos sólidos urbanos: o programa de coleta seletiva da região metropolitana de Belém - PA. 2012. $111 \mathrm{f}$. [Dissertação de Mestrado] Curso de Mestrado em Desenvolvimento e Meio Ambiente Urbano, Universidade da Amazônia Programa de Mestrado, Unama, Belém- PA, 2012.

ONUBR. OMS define 10 prioridades de saúde para 2019. Disponível em:

https://nacoesunidas.org/oms-define-10-prioridades-de-saude-para-2019/. Acesso em: 19 fev. 2019.

POLZIN, Deolinda Alexandra Oliveira Fernandes Moreira. Gestão dos resíduos sólidos urbanos: análise comparativa entre Portugal e Brasil. 2004. 78 f. [Dissertação de Mestrado] Curso de Ciência Ambiental, Instituto Geociência, Universidade Federal Fluminense, Niterói, 2004.

SANTAELLA, S. T. et al. Resíduos sólidos e a atual política ambiental brasileira. 7. ed. Fortaleza: Labomar, 2014. p.231.

SANTOS, A.R.S. Relato de Experiência: Educação Ambiental nas Atividades Didáticas com as Crianças do 20 ano do Ensino Fundamental. Educon, Aracaju, Volume 11, n.

01, p.1-7, set/2017. Anais...XI Colóquio Internacional: Educação e

Contemporaneidade. São Cristóvão-SE.

SILVA, Ana Paula Moreira; Viana, João Paulo; Cavalcante, André Luís Brasil Cavalcante. Diagnóstico dos Resíduos Sólidos da Atividade de Mineração de Substâncias Não Energéticas. IPEA: Brasília, 2012.

SILVA, Eulália Cristina. Sensibilização da comunidade escolar de alguns municípios paraibanos em relação ao descarte dos resíduos sólidos gerados na escola. 2015. 46 f. [Dissertação de Mestrado] - Curso de Licenciatura em Química, Departamento de Química, Universidade Estadual de Paraíba, Campina Grande-PB, 2015.

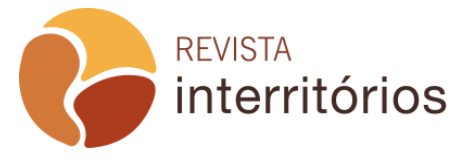


SILVA, Jackson Ronie; ALMEIDA, Cristóvão Domingos de; GUINDANI, Joel Felipe. Pesquisa documental: pistas teóricas e metodológicas. Revista Brasileira de História \& Ciências Sociais, Rio Grande do Sul, v. 01, n. 01, p.1-15, jul. 2009. Anualmente.

SOARES, Liliane Gadelha da Costa; SALGUEIRO, Alexandra Amorim; GAZINEU, Maria Helena Paranhos. Educação ambiental aplicada aos resíduos sólidos na cidade de Olinda, Pernambuco: um estudo de caso. Revista Ciências \& Tecnologia: Centro de Ciências e Tecnologia, Recife-PE, v. 1, n. 9, p. 1-9, 01 dez. 2007. Semestralmente.

TÉLA-NÓN. Como vai A Gestão de resíduos em São Tomé e Príncipe. 2010.

Disponível em: https://goo.gl/QfmQjN. Acesso em: 13 jan. 2018.

TESE; EcoGestus. Plano Nacional de Gestão Integrada de Resíduos Sólidos Urbanos (PNGIRSU) 2018-2023. Disponível em:

https://issuu.com/joaovaz71/docs/s_otom_plano_res_duos_final_2018. Acesso em 19 abr 2020.

VEIGA, Abel. Poder local de água grande reforça política de gestão dos

resíduos. 2012. Disponível em: https://goo.gl/JgQMmz. Acesso em: 15 jan. 2018.

VEIGA, Abel. Lixo que está a engolir a capital e os arredores pode ser tratado. TÉLA NÓN. São Tomé, 23 fev. 2016. p. 1-2. Disponível em:

https://www.telanon.info/sociedade/2016/02/23/21241/lixo-que-esta-a-engolir-a-capitale-os-arredores-pode-ser-tratado/. Acesso em: 08 maio 2018. 